\title{
BMJ Open Modification of maternal late pregnancy sleep position: a survey evaluation of a New Zealand public health campaign
}

\author{
Robin S Cronin (1) ,1,2 John M D Thompson (i) , ${ }^{3}$ Rennae S Taylor, ${ }^{1}$ \\ Jessica Wilson (D) ${ }^{3}$ Karen F Falloon, ${ }^{4}$ Sophie Skelton, ${ }^{1}$ Elsie Brown, ${ }^{1}$ \\ Vicki M Culling, ${ }^{1,5}$ Edwin A Mitchell, ${ }^{3}$ Lesley M E McCowan, ${ }^{1}$ The Maternal Sleep \\ Position Awareness Campaign Team
}

To cite: Cronin RS,

Thompson JMD, Taylor RS, et al. Modification of maternal late pregnancy sleep position: a survey evaluation of a New Zealand public health campaign. BMJ Open 2021;11:e047681. doi:10.1136/ bmjopen-2020-047681

- Prepublication history and additional supplemental material for this paper are available online. To view these files, please visit the journal online (http://dx.doi.org/10.1136/ bmjopen-2020-047681)

Received 07 December 2020 Revised 16 April 2021 Accepted 20 April 2021

Check for updates

(C) Author(s) (or their employer(s)) 2021. Re-use permitted under CC BY-NC. No commercial re-use. See rights and permissions. Published by BMJ.

For numbered affiliations see end of article.

Correspondence to

Dr Robin S Cronin;

r.cronin@auckland.ac.nz

\section{ABSTRACT}

Introduction A 'Sleep-On-Side When Baby's Inside' public health campaign was initiated in New Zealand in 2018. This was in response to evidence that maternal supine going-to-sleep position was an independent risk factor for stillbirth from 28 weeks' gestation. We evaluated the success of the campaign on awareness and modification of late pregnancy going-to-sleep position through nationwide surveys.

Methods and analysis Two web-based cross-sectional surveys were conducted over 12 weeks in 2019-2020 in a sample of (1) pregnant women $\geq 28$ weeks, primary outcome of going-to-sleep position; and (2) health professionals providing pregnancy care, primary outcome of knowledge of going-to-sleep position and late stillbirth risk. Univariable logistic regression was performed to identify factors associated with supine going-to-sleep position

Discussion The survey of pregnant women comprised 1633 eligible participants. Going-to-sleep position last night was supine $(30,1.8 \%)$, non-supine $(1597,97.2 \%)$ and no recall $(16,1.0 \%)$. Supine position had decreased from $3.9 \%$ in our previous New Zealand-wide study (2012-2015). Most women (1412, 86.5\%) had received sleep-on-side advice with no major resultant worry (1276, $90.4 \%)$. Two-thirds $(918,65.0 \%)$ had changed their going-to-sleep position based on advice, with most $(611$ of $918,66.5 \%)$ reporting little difficulty. Supine position was associated with Māori (OR 5.05, 95\% Cl 2.10 to 12.1) and Asian-non-Indian (OR 4.20, 95\% Cl 1.27 to 13.90) ethnicity; single (OR 10.98, $95 \% \mathrm{Cl} 4.25$ to 28.42$)$ and cohabitating relationship status (OR $2.69,95 \% \mathrm{Cl} 1.09$ to 6.61); hospital-based maternity provider (OR $2.55,95 \% \mathrm{Cl}$ 1.07 to 6.10$)$ ); education overseas (OR $3.92,95 \% \mathrm{Cl}$ 1.09 to 14.09 ) and primary-secondary level (OR 2.80, $95 \% \mathrm{Cl} 1.32$ to 6.08$)$; and not receiving sleep-on-side advice (OR 6.70, 95\% $\mathrm{Cl} 3.23$ to 13.92). The majority of health professionals (709 eligible participants) reported awareness of supine going-to-sleep position and late stillbirth risk (543, 76.6\%).

Conclusion Most pregnant women had received and implemented sleep-on-side advice without major difficulty or concern. Some groups of women may need a tailored approach to acquisition of going-to-sleep position information.
Strengths and limitations of this study

- This is the first study to evaluate the success of a nationwide public health campaign on awareness and modification of late pregnancy going-to-sleep position

- Responses were obtained from a New Zealand-wide convenience sample of pregnant women, with enrichment from socioeconomically disadvantaged communities that have an associated increased risk of stillbirth and health professionals who provide pregnancy care.

- Maternal late pregnancy going-to-sleep position was self-reported and not able to be validated, although maternal recall of going-to-sleep position last night is known to be largely accurate.

- The decreasing prevalence of supine going-to-sleep position resulted in low numbers of women in this group.

\section{INTRODUCTION}

Late stillbirth in the third trimester of pregnancy is a tragedy for everyone involved. It is also a public health problem that affects 2.4 in every 1000 pregnant women in New Zealand, with approximately 150 normally formed babies stillborn annually. ${ }^{1}$ Nearly one-third of these stillbirths are classified as 'unexplained'. If readily modifiable risk factors could be identified, some late stillbirths could be prevented.

The Auckland Stillbirth Study (TASS) ${ }^{2}$ was the first to show that women who reported going to sleep supine in the third trimester had a 2.5-fold increased risk of late stillbirth that was independent of other known major risk factors for stillbirth. This finding was biologically plausible and aligned with existing research on the effects of maternal supine position in the third trimester demonstrating vena-caval compression, ${ }^{3-5}$ decreased maternal cardiac output, ${ }^{46}$ increased maternal heart rate, ${ }^{4578}$ decreased uterine perfusion ${ }^{89}$ 
and lower fetal oxygen saturation, ${ }^{10}{ }^{11}$ compared with leftside maternal position.

This led to the New Zealand-wide Multicentre Stillbirth Study (MCSS), ${ }^{12}$ which reported maternal supine goingto-sleep position was associated with a 3.7 -fold increase in overall late stillbirth risk. Australian, ${ }^{13} \mathrm{UK}^{14}$ and USAbased $^{15}$ studies on late pregnancy sleep position and stillbirth have reported a similar association. Data from these and the two New Zealand studies were pooled in an individual participant data (IPD) meta-analysis. ${ }^{16}$ The IPD confirmed that maternal supine going-to-sleep position was an independent risk factor for late stillbirth in the third trimester (adjusted odds ratio [aOR] 2.63, 95\% Confidence Interval [CI]1.72 to 4.04) and the risk was applicable to all pregnant women.

The New Zealand 'Sleep-On-Side When Baby's Inside' national public health campaign ${ }^{17}$ was developed with the aim to increase awareness of late pregnancy goingto-sleep position and provide information for pregnant women and health professionals. With support from the New Zealand Ministry of Health and key professional and consumer bodies, online (Facebook and video) and written resources (pamphlets and posters) were developed and disseminated to pregnant women and health professionals through professional bodies, a campaign website (https://www.sleeponside.org.nz/), media articles and conference presentations. The pamphlet was released in a number of languages, including Māori, Sāmoan, Hindi, Tongan and English,${ }^{18}$ and is freely available. The video provided sleep-on-side advice using the popular nursery song 'there were two in the bed and the little one said roll over'. The video was modified for the New Zealand campaign, with a New Zealand narrator and singing in Māori language, with permission from Tommy's UK charity. ${ }^{19}$ The main messages of the campaign were to start every sleep on the side, including going to sleep at night, returning to sleep after any night awakenings and daytime naps.

It may be several years before national perinatal mortality data ${ }^{20}$ showing the predicted impact of the change in maternal going-to-sleep position on stillbirth rates are available. This is because late stillbirth is relatively uncommon and the annual national perinatal mortality publication reports on data that are 2 years old. Therefore, we planned an intermediate step to measure awareness and modification of maternal late pregnancy going-to-sleep position as a variable that is causally related to stillbirths. ${ }^{212} 16$

We sought to evaluate the effectiveness of the New Zealand campaign for (1) pregnant women in the third trimester and (2) health professionals who provide care for pregnant women. We aimed to determine if pregnant women's knowledge about going-to-sleep position and reported position differed by demographic characteristics; if pregnant women who have received advice about going-to-sleep position are less likely to report going to sleep supine; if pregnant women are less likely to report they go-to-sleep supine compared with historical New
Zealand data; and if knowledge of supine going-to-sleep position and association with late stillbirth differs between groups of health professionals who provide care for pregnant women.

\section{METHODS AND ANALYSIS}

\section{Study design and participants}

This study followed the research protocol (online supplemental file 1), accessible at figshare (doi: 10.17608/ k6.auckland.13298504). Two anonymous cross-sectional surveys (online supplemental file 1) were undertaken over a 12-week period between November 2019 and March 2020. Eligible participants were (1) pregnant women with a singleton baby $\geq 28$ weeks' gestation, $\geq 16$ years of age, living in New Zealand and who completed the survey; and (2) health professionals who provide pregnancy care in New Zealand and who completed the survey (table 1). The self-administered surveys were undertaken using a web-based survey software tool (Qualtrics, Provo, Utah).

\section{Patient and public involvement}

Representatives from key professional and consumer bodies have been research partners in all aspects of the campaign. These have included developing and disseminating the campaign resources and subsequent campaign evaluation to pregnant women and health professionals, and contributing to this paper.

\section{Data collection}

Pregnant women's survey

An internet link to the recruitment page for the webbased survey was promoted to pregnant women through Facebook. An invitation containing the internet link was also emailed via key health professional and consumer networks to support participation of women throughout New Zealand (including in small centres and rural areas). To support recruitment of an ethnically diverse sample of women from an area of high deprivation and increased risk of stillbirth, an invitation to participate in the survey via an electronic tablet or laptop was offered face-to-face by a research assistant to pregnant women attending antenatal clinics in the Auckland District Health Board and Counties Manukau Health regions in Auckland City over a 6-week period.

\section{Health professionals' survey}

An invitation email with an internet link to the recruitment page for web-based survey was distributed via the health professional organisations and networks to their members. To support recruitment of eligible health professionals, general practitioner practices in the Counties Manukau Health and Northland regions were contacted by a researcher or assistant, and health professional staff were invited to participate. If agreed, the study information containing a link to the survey was emailed to the practice for distribution to the health professional staff. 
Table 1 Study-level characteristics of pregnant women's and health professionals' surveys

\begin{tabular}{|c|c|c|}
\hline $\begin{array}{l}\text { Study-level } \\
\text { characteristics }\end{array}$ & Pregnant women's survey & Health professionals' survey \\
\hline Study design & Web-based survey. & Web-based survey. \\
\hline $\begin{array}{l}\text { Recruitment } \\
\text { timeframe }\end{array}$ & 20 November 2019-20 February 2020. & 1 December 2019-31 March 2020. \\
\hline Data collection & $\begin{array}{l}\text { Facebook advertisement linking to study- } \\
\text { specific University of Auckland recruitment } \\
\text { web page. } \\
\text { Email invitation containing a link to the } \\
\text { recruitment web page sent via professional } \\
\text { consumer networks, including Parents' } \\
\text { Centre New Zealand, Sands New Zealand, } \\
\text { Rural Women New Zealand and Women's } \\
\text { Health Action. } \\
\text { Face-to-face invitation from a research } \\
\text { assistant at community antenatal clinics } \\
\text { to participate via the research assistant's } \\
\text { tablet/laptop linked to the study-specific } \\
\text { University of Auckland recruitment web } \\
\text { page. }\end{array}$ & $\begin{array}{l}\text { Email invitation containing a link to the study-specific } \\
\text { University of Auckland recruitment web page sent via } \\
\text { health professional networks, including the New Zealand } \\
\text { College of Midwives, Ngā Māia ki Tāmaki Makaurau } \\
\text { Māori Midwives, Pasifika Midwives Aotearoa, Royal } \\
\text { Australian and New Zealand College of Obstetricians } \\
\text { and Gynaecologists, Royal New Zealand College of } \\
\text { General Practitioners, Nurse Practitioners New Zealand, } \\
\text { New Zealand College of Primary Health Care Nurses, } \\
\text { and New Zealand Nurses Organisation. } \\
\text { Phone invitation from a researcher/research assistant } \\
\text { to general practitioner practices to participate via an } \\
\text { email containing a link to the study-specific University of } \\
\text { Auckland recruitment web page. }\end{array}$ \\
\hline Population & $\begin{array}{l}\text { Pregnant women with a singleton } \\
\text { pregnancy, } \geq 28 \text { weeks' gestation, } \geq 16 \\
\text { years of age, living in New Zealand. }\end{array}$ & $\begin{array}{l}\text { Health professionals who currently provide care for } \\
\text { pregnant women in New Zealand. }\end{array}$ \\
\hline Measures & $\begin{array}{l}\text { Age. } \\
\text { Ethnicity. } \\
\text { Country of birth. } \\
\text { Geographical location. } \\
\text { Height. } \\
\text { Weight (first pregnancy, current). } \\
\text { Parity. } \\
\text { - Gestational age at first pregnancy visit. } \\
\text { - Marital status. } \\
\text { - } \text { Maternity scale. } \\
\text { - Sleep environiders. } \\
\text { - Late pregnancy going-to-sleep position: } \\
\text { knowledge acquisition and views. }\end{array}$ & $\begin{array}{l}\text { Professional role. } \\
\text { Geographical location. } \\
\text { Late pregnancy going-to-sleep position: knowledge } \\
\text { acquisition, advice offered to pregnant women and views } \\
\text { about advice. }\end{array}$ \\
\hline $\begin{array}{l}\text { Primary outcome } \\
\text { measure }\end{array}$ & Supine going-to-sleep position last night. & $\begin{array}{l}\text { Knowledge of supine going-to-sleep position and late } \\
\text { stillbirth risk. }\end{array}$ \\
\hline
\end{tabular}
stillbirth risk.

\section{Measures}

Pregnant women's survey

Data collected were self-reported and included maternal age, prioritised ethnicity, country of birth, geographical location of residence, height and weight, parity, gestational age at first pregnancy visit, marital status, education, health professionals providing maternity care, gestation at first pregnancy visit, current gestation in weeks, expected date of birth, current sleep environment, knowledge acquisition and views of late pregnancy going-to-sleep position. Sleep-on-side advice responses comprised the recommendation to go to sleep on either side, left side, right side, avoid your back and go-to-sleep with a pillow behind your back/between your knees. No sleep-on-side advice responses comprised go-to-sleep in the most comfortable position and no sleep position advice. Scores for anxiety using the State-Trait Anxiety Inventory (STAI-6 scale, a short version of STAI-20 scale $)^{21}$ were assessed at the beginning of the survey, with scores $\geq 50$ indicating high anxiety. Prioritised ethnicity was reported according to the New Zealand Ministry of Health protocols. ${ }^{22}$ Maternal body mass index (BMI) was calculated as weight $(\mathrm{kg}) /$ height $(\mathrm{m})^{2}$ and classified according to conventional $\mathrm{WHO}^{23}$ criteria. Some women reported that more than one health professional was providing their maternity care, therefore, this response was prioritised by the health professional who was the lead maternity provider. 


\section{Health professionals' survey} ical location, knowledge acquisition and views of late pregnancy going-to-sleep position, and advice offered to pregnant women on going-to-sleep position. Health professional role is defined as midwife continuity of care (community-based continuity of care midwife), midwife other (hospital-based and educational institution-based midwife), obstetric doctor employed in a hospital, general practitioner, nurse (community-based primary care and hospital-based) and other (childbirth educator, other community-based health provider).

\section{Data analysis}

Pregnant women's survey

Descriptive statistics were used to describe the study population and summarise the data, including demographic characteristics, going-to-sleep position and late pregnancy sleep knowledge. The STAI scale was assessed at the beginning of the survey. Univariable analysis was performed to evaluate the association between demographic variables, sleep knowledge and the odds of supine going-to-sleep position. The timeframe for analysis was last night, as this is considered relatively accurate. ${ }^{24}$ Significance was defined at the $5 \%$ level and analysis carried out using SAS V.9.4. Estimates of the odds of supine going-to-sleep position were reported as OR with $95 \%$ CI. The sample size was based on a 3.9\% (22 of 569) prevalence of supine going-to-sleep position in the control participants in our New Zealand-wide stillbirth case-control study ${ }^{12}$ and a type 1 error of $5 \%$ and power of $80 \%$. A sample size of 569 participants was required to detect a change in supine going-to-sleep position from a prevalence of $3.9 \%$ to $1.3 \%$.
Data collected included professional role and geograph-

Health professionals' survey

Professional grouping and geographical location were used to describe the study population. Knowledge of goingto-sleep position and late stillbirth risk and the provision of sleep-on-side campaign resources (pamphlet, poster and online video) were explored using logistic regression. Estimates of knowledge and provision of resources on supine going-to-sleep position were reported as OR with 95\% CI. No specific power calculation was performed for this component of the study; simply the intention was to include as many participants as possible for preciseness of estimates.

\section{RESULTS}

The survey of pregnant women (figure 1) had 2219 respondents, and of these $1633(73.6 \%)$ were eligible. Women who reported multiple pregnancy $(n=35),<28$ weeks' gestation $(n=62)$, post partum at participation $(n=222)$ or with an incomplete survey $(n=267)$ were excluded from the analysis.

The median gestation at survey completion was 34.0 (IQR 30-37) weeks. The majority of pregnant participants were born in New Zealand $(70.7 \%, \mathrm{n}=1154)$. For those born overseas, the median number of years in New Zealand was 8.0 (IQR 4.0-16.0). The study population was similar to the New Zealand birthing population, ${ }^{1}$ with a median age of 30 years and the largest proportion $(n=905,57.7 \%)$ of women residing outside the Auckland region. Ethnicities were also comparable, with some over-representation of European $(58.0 \%$ vs $44.6 \%)$ and under-representation of Māori (16.0\% vs $25.0 \%)$ and Asian-non-Indian (6.3\% vs $11.4 \%$ ) (online supplemental file 2, table A).

Going-to-sleep position last night was supine $(30,1.8 \%)$, non-supine $(1597,97.2 \%)$ and no recall $(16,1.0 \%)$. In the univariable analysis, five factors were significantly

Health Professionals' Survey
Total respondents: $\mathrm{N}=758$
Eligibility criteria: health professional currently
providing care for pregnant women living in New
Zealand, and completed the survey

Total respondents: $\mathrm{N}=2219$

Eligibility criteria: pregnant women $\geq 28$ weeks' gestation with singleton pregnancy, $\geq 16$ years of age, living in New Zealand, and completed the survey

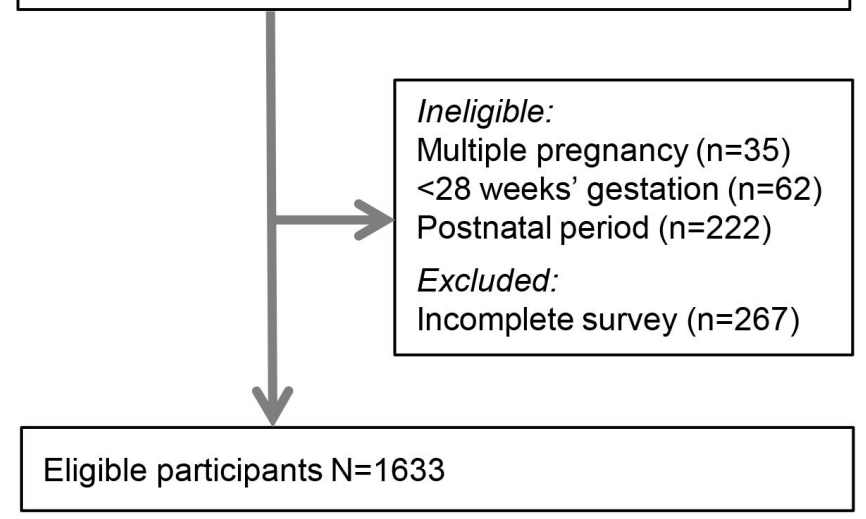

Figure 1 Flow chart of study population for pregnant women's and health professionals' surveys. 
Table 2 Pregnant women's survey: demographic factors and sleep-on-side advice associated with going-to-sleep position last night

\begin{tabular}{|c|c|c|c|}
\hline Variable & $\begin{array}{l}\text { Supine last night } \\
\mathrm{n}=30\end{array}$ & $\begin{array}{l}\text { Non-supine last night } \\
n=1587\end{array}$ & Univariable OR $(95 \% \mathrm{Cl})$ \\
\hline Gestation at participation & $34.0(30.0-37.0)$ & $34.0(30.0-37.0)$ & 1.03 (0.93 to 1.13$)$ \\
\hline Maternal age (years) & $29.0(23.0-34.0)$ & $30.0(26.0-33.0)$ & 0.98 (0.92 to 1.05$)$ \\
\hline \multicolumn{4}{|l|}{ Ethnicity } \\
\hline European & $9(30.0)$ & $927(58.4)$ & 1 \\
\hline Māori & $12(40.0)$ & $245(15.4)$ & 5.05 (2.10 to 12.1$)$ \\
\hline Pacific & $5(16.7)$ & $172(10.8)$ & 2.99 (0.99 to 9.04$)$ \\
\hline Indian & 0 & $88(5.6)$ & - \\
\hline Asian-non-Indian* & $4(13.3)$ & $98(6.2)$ & $4.20(1.27$ to 13.90$)$ \\
\hline Other ethnicity & 0 & $57(3.4)$ & - \\
\hline \multicolumn{4}{|l|}{ Marital status } \\
\hline Single & $10(33.3)$ & $108(6.8)$ & 10.98 (4.25 to 28.42$)$ \\
\hline Cohabitating couple & $12(40.0)$ & $530(33.4)$ & 2.69 (1.09 to 6.61$)$ \\
\hline Married couple & $8(26.7)$ & 949 (59.8) & 1 \\
\hline \multicolumn{4}{|l|}{ Parity } \\
\hline 0 & $16(53.3)$ & $861(54.3)$ & $0.96(0.47$ to 1.99$)$ \\
\hline $1+$ & $14(46.7)$ & $726(45.8)$ & 1 \\
\hline \multicolumn{4}{|l|}{ Lead maternity provider } \\
\hline Midwifery continuity of care & $21(70.0)$ & $1310(82.6)$ & 1 \\
\hline Private obstetrician & $2(6.7)$ & $106(6.7)$ & 1.18 (0.27 to 5.09$)$ \\
\hline Hospital-based midwife/doctor & $7(23.3)$ & $171(10.8)$ & 2.55 (1.07 to 6.10$)$ \\
\hline \multicolumn{4}{|l|}{ Education level } \\
\hline Primary-secondary & $14(46.7)$ & $419(26.4)$ & 2.80 (1.32 to 6.08$)$ \\
\hline Tertiary & $13(43.3)$ & $1103(69.5)$ & 1 \\
\hline Overseas & $3(10.0)$ & $65(4.1)$ & $3.92(1.09$ to 14.09$)$ \\
\hline \multicolumn{4}{|l|}{ Location } \\
\hline Urban & $19(63.3)$ & $1087(68.5)$ & 1 \\
\hline Rural & $11(36.7)$ & $500(31.5)$ & 1.26 (0.60 to 2.66$)$ \\
\hline Gestation at first pregnancy visit & $8.5(6.5-12.0)$ & $8.0(6.0-10.0)$ & 1.04 (0.97 to 1.12$)$ \\
\hline First pregnancy body mass index $\left(\mathrm{kg} / \mathrm{m}^{2}\right)$ & $27.1(21.5-32.1)$ & $25.1(22.4-30.1)$ & 1.03 (0.98 to 1.09$)$ \\
\hline \multicolumn{4}{|l|}{ Received sleep-on-side advice } \\
\hline Yes & $15(50.0)$ & $1381(87.0)$ & 1 \\
\hline No & $15(50.0)$ & 206 (13.0) & 6.70 (3.23 to 13.92$)$ \\
\hline
\end{tabular}

Data are column number (percentage) or median (IQR).

Participants with no recall of going-to-sleep position last night $(n=16)$ were excluded from the univariable model.

*Asian-non-Indian includes South East Asian $(n=56)$, Chinese $(n=31)$ and Asian other $(n=25)$.

associated with pregnant women reporting a supine goingto-sleep position last night (30 of 1633, 1.8\%) (table 2). These were Māori (OR 5.05, 95\% CI 2.10 to 12.1) and Asian-non-Indian ethnicity (OR 4.20, 95\% CI 1.27 to 13.90) compared with European; single (OR 10.98, 95\% CI 4.25 to 28.42) and defacto relationship status (OR 2.69, 95\% CI 1.09 to 6.61 ) compared with married; hospitalbased midwife/doctor as lead maternity provider (OR $2.55,95 \%$ CI 1.07 to 6.10 ) compared with a continuity of care midwife; education to primary-secondary level (OR
$2.80,95 \%$ CI 1.32 to 6.08 ) and overseas (OR 3.92, $95 \%$ CI 1.09 to 14.09 ) compared with tertiary-level education; and no recall of receiving sleep-on-side advice from any source (OR 6.70, 95\% CI 3.23 to 13.92) compared with receiving advice. Gestation at participation, maternal age, parity, geographical location, gestation at first antenatal visit and first pregnancy BMI were not significantly related to supine going-to-sleep position last night.

The low number of pregnant women reporting a supine going-to-sleep position last night (30 of 1633, 1.8\%) and 
the sparseness of some categorical variables precluded us from undertaking multivariable analysis to investigate the independent associations between maternal characteristics, models of pregnancy care and going-to-sleep position.

Midwives and doctors were more likely to provide going-to-sleep position information than other sources (table 3). Advice from a midwife/doctor was reported by 1016 of 1633 (62.2\%) pregnant participants, while advice from other sources (including internet, family and friends, pamphlet, childbirth educator, phone app, social and print media) was reported by 698 (42.7\%), with many women selecting multiple sources (online supplemental file 2 , table B). Only 302 women $(18.5 \%)$ received sleep position advice from both their midwife/doctor and from other sources.

Advice to choose the most comfortable position was reported by $125(7.7 \%)$ women, and 122 of these women reported this was combined with sleep-on-side advice. No sleep position advice from any source was reported by 218 women. Health professionals were more likely to have viewed both the pamphlet/poster and video than pregnant women (pamphlet $60.5 \%$ vs $22.2 \%$; video $18.5 \%$ vs $3.0 \%)$.

Nearly two-thirds of women (918 of 1412, 65.0\%) reported they had changed their going-to-sleep position based on advice, and the majority (611 of 918, 66.5\%) reported no major difficulty making this change. Around half (406 of 918, 44.2\%) of those who changed position reported that their previous position was supine. Among those who needed help to change (720 of 918, 78.4\%), pillows were the most popular aid (675 of $720,93.8 \%$ ).

The median gestation of position change was 20.0 weeks (IQR 15.0-25.0), with two-thirds $(602,67.0 \%)$ changing position in the second trimester. Of the women (494 of $1412,35 \%$ ) who did not change position following sleepon-side advice, almost all (491 of 494, 99.4\%) reported a non-supine going-to-sleep position last week.

Most (1493 of 1633, 91.6\%) women reported that they slept in a bed that was queen-sized or larger (online supplemental file 2, table C). Sleeping alone at night was uncommon (124, 7.6\%), with 1509 women (92.4\%) sharing the bed with a partner, another adult, children or pet, or a combination of these.

The reasons for adopting their going-to-sleep position last week for pregnant women who had received sleepon-side advice were predominantly 'better for baby' (858, $60.8 \%)$ and comfort $(732,41.6 \%)$ (online supplemental file 2 , table C). Of the 212 women who were unaware of the sleep-on-side campaign message, the most common reason for their choice of going-to-sleep position last week was comfort (144 of 221, 65.2\%), with none reporting 'better for baby'.

Most (1276 of 1412, 90.3\%) pregnant women who had received sleep-on-side advice reported that this resulted in minimal or no worry, with only $35(2.5 \%)$ very worried by the advice. Of the 1406 women who completed the STAI score (table 4), 236 (16.8\%) had a high score. There was
Table 3 Pregnant women's survey: going-to-sleep position advice sources and actions

\begin{tabular}{ll}
\hline Advice from midwife/doctor only & $\mathbf{n}=1633$ \\
\hline Either side/non-supine & $802(49.1)$ \\
\hline Left side only & $199(12.2)$ \\
\hline Right side only & $3(0.2)$ \\
\hline Pillow behind back/between knees only & $12(0.7)$ \\
\hline Most comfortable position only & $3(0.2)$ \\
\hline No sleep position advice & $614(37.6)$ \\
\hline Advice from other sources only & $\mathbf{n}=1633$ \\
\hline Either side/non-supine & $557(34.1)$ \\
\hline Left side only & $131(8.0)$ \\
\hline Right side only & $6(0.4)$ \\
\hline Pillow behind back/between knees only & $4(0.2)$ \\
\hline Most comfortable position only & $1(0.1)$ \\
\hline No sleep position advice & $934(57.2)$ \\
\hline Total advice combined (midwife/doctor & $\mathbf{n}=1633$ \\
and other sources) & \\
\hline Either side/non-supine & $1142(69.9)$ \\
\hline Left side only & $251(15.4)$ \\
\hline Right side only & $7(0.4)$ \\
\hline Pillow behind back/between knees only & $12(0.7)$ \\
\hline Most comfortable position only & $3(0.2)$ \\
\hline No sleep position advice & $218(13.3)$ \\
\hline Usual going-to-sleep position last week & $\mathbf{n}=1633$ \\
\hline Supine & $19(1.2)$ \\
\hline Non-supine & $1585(97.0)$ \\
\hline No particular position & $29(1.8)$ \\
\hline Changed position due to advice & $\mathbf{n}=1633$ \\
\hline Yes changed position & $918(56.2)$ \\
\hline No position change & $494(30.3)$ \\
\hline Most comfortable position only & $3(0.2)$ \\
\hline No sleep position advice & $218(13.3)$ \\
\hline $\begin{array}{l}\text { Position before change (of those who } \\
\text { changed) }\end{array}$ & $\mathbf{n}=918$ \\
\hline Let side & $18(2.0)$ \\
\hline
\end{tabular}

\begin{tabular}{ll} 
Left side & $18(2.0)$ \\
\hline Supine & $406(44.2)$ \\
\hline Right side & $72(7.8)$ \\
\hline Prone & $275(30.0)$ \\
\hline Propped up & 0 \\
\hline Either side & $57(6.2)$ \\
\hline No particular position & $85(9.3)$ \\
\hline No recall & $5(0.5)$ \\
\hline $\begin{array}{l}\text { Difficulty with change (of those who } \\
\text { changed) }\end{array}$ & $\mathbf{n}=918$ \\
\hline Not difficult & $174(18.9)$ \\
\hline Somewhat difficult & $437(47.6)$ \\
\hline Moderately difficult & $210(22.9)$ \\
\hline & Continued
\end{tabular}

Continued 


\begin{tabular}{ll}
\hline Table 3 Continued & \\
\hline Very difficult & $97(10.6)$ \\
\hline Help with change (of those who changed) & $\mathbf{n}=918$ \\
\hline Yes help required & $720(78.4)$ \\
\hline No help required & $199(21.6)$ \\
\hline Gestation of change (trimester) & $\mathbf{n}=918$ \\
\hline First trimester & $183(18.1)$ \\
\hline Second trimester & $602(67.0)$ \\
\hline Third trimester & $134(13.9)$ \\
\hline Gestation of change (median gestation week) & $20.0(1 \mathrm{R}$ \\
& $15.0-25.0)$ \\
\hline Changed position due to advice and & $\mathbf{n}=720$ \\
\hline required help (multiple choice answer) & \\
\hline Pillow between knees/legs & $424(59.0)$ \\
\hline Body pillow (long or shaped pillows/wedges) & $301(41.8)$ \\
\hline Pillow behind back & $292(40.5)$ \\
\hline Pillow under abdomen & $243(33.8)$ \\
\hline Partner reminded woman & $94(13.0)$ \\
\hline Changed side of bed & $78(10.1)$ \\
\hline Tied hair into a bun & $26(3.6)$ \\
\hline Partner moved to another bed & $24(3.3)$ \\
\hline Woman moved to another bed & $13(1.8)$ \\
\hline Choman moved to chair & $9(1.3)$ \\
\hline Children moved to another bed & $6(0.8)$ \\
\hline
\end{tabular}

Data are column number (percentage) or median (IQR).

a significant relationship between women's level of worry and STAI score $\left(\chi_{3}^{2}=15.75, \mathrm{p}=0.001\right)$; however, most (204 of $236,86.4 \%$ ) of those with high STAI scores reported minimal or no worry following receipt of sleep-on-side advice.

The health professionals' survey (figure 1) had 758 respondents; 709 completed the survey and were eligible.

Table 4 Pregnant women's survey: worry following sleepon-side advice by State-Trait Anxiety Inventory (STAI) score

\begin{tabular}{llll}
\hline & $\begin{array}{l}\text { STAl normal } \\
\text { score } \\
\mathbf{n = 1 1 7 1}\end{array}$ & $\begin{array}{l}\text { STAI high } \\
\text { score* }^{*}\end{array}$ & $\begin{array}{l}\text { Total } \\
\mathbf{n}=236\end{array}$ \\
Worry & $\mathbf{n}$ (column \%) & $\mathbf{n}$ (column \%) & $\mathbf{n}$ (column \%) \\
\hline Not at all & $613(52.4)$ & $94(39.8)$ & $707(50.3)$ \\
Somewhat & $453(38.7)$ & $110(46.6)$ & $563(40.0)$ \\
Moderately & $80(6.8)$ & $21(8.9)$ & $101(7.2)$ \\
Very much & $24(2.1)$ & $11(4.7)$ & $35(2.5)$ \\
\hline
\end{tabular}

*High STAI score is $\geq 50$ and indicates high situation specific and personal trait anxiety.
Of those eligible 709 health professionals, 605 (85.3\%) provided sleep-on-side advice, and this was more likely for midwives compared with doctors, nurses and other health professionals (online supplemental file 2, table D). Some health professionals $(104,17.2 \%)$ had been unaware of the association with late stillbirth before this study, but commented in free text that they usually advised pregnant women to sleep on the side for the women's comfort and fetal well-being. General practitioners and nurses who provided healthcare for pregnant women, but were not lead maternity providers, were less likely to be aware of the association between late pregnancy going-to-sleep position and stillbirth risk compared with midwives providing continuity of care.

Most (501 of 543, 92.3\%) health professionals who were aware of the association between late pregnancy going-to-sleep position and stillbirth risk provided women with sleep-on-side advice, and another 38 (7\%) reported they had no opportunity to provide advice due to limited contact with women in late pregnancy, and only $4(0.7 \%)$ health professionals knowingly chose not to provide advice. Knowledge of the sleep-on-side campaign pamphlet was reported by the majority of health professionals $(429,60.5 \%)$, although fewer $(131,18.5 \%)$ had viewed the video (online supplemental file 2, table B).

Participants in both the pregnant women's survey and the health professionals' survey were asked if they believed all pregnant women should be given advice about late pregnancy going-to-sleep position and stillbirth risk (online supplemental file 1 ). The large majority of pregnant women $(1499,91.8 \%)$ and health professionals $(685,96.6 \%)$ selected 'yes' (online supplemental file 2, table E), including most pregnant women (184 of $221,83.3 \%$ ) and health professionals (154 of 166, 92.8\%) who had been unaware of the association between supine sleep and stillbirth risk prior to participating in the survey. Health professionals who reported 'no' or 'unsure' in response to the question (some selecting more than one response) cited lack of knowledge about late pregnancy going-to-sleep position and stillbirth risk $(n=15)$, lack of belief in the knowledge $(n=15)$, and concern about potential to create anxiety in pregnant women $(n=12)$.

The proportion of women with a singleton pregnancy $\geq 28$ weeks' gestation and living in New Zealand who reported a supine going-to-sleep position last night has been decreasing over the past decade: TASS (2007-2009, $4.6 \%)$, MCSS (2012-2015, 3.9\%), South Auckland Sleep Survey $(2014,3.2 \%)$ and this survey (2019-2020, 1.8\%) $\left(X^{2}\right.$ test for trend $\left.=11.37, p=0.0007\right){ }^{2}{ }^{1225}$

\section{DISCUSSION}

Our surveys were conducted in a sample of (1) pregnant women in the third trimester and (2) health professionals who provide care for pregnant women in New Zealand. These surveys report findings on the effectiveness of the New Zealand 'Sleep-On-Side When Baby's Inside' campaign on awareness and modification of maternal 
late pregnancy going-to-sleep position. Importantly, pregnant women who received sleep-on-side advice were less likely to report going to sleep supine last night. We also found that sleep position differed by demographic characteristics. In addition, we confirmed that the prevalence of supine sleep position in late pregnancy has continued to decline in New Zealand, with change to a non-supine position occurring in the majority around 20 weeks' gestation. We also demonstrated that knowledge of supine going-to-sleep position and late stillbirth risk differed between groups of health professionals who provide pregnancy care.

It was reassuring that 18 months since the public health campaign, the large majority of pregnant participants reported that their going-to-sleep position last night was non-supine, with just $1.8 \%$ reporting the supine going-tosleep position. In univariable analysis, the rate of supine position differed by demographic factors: ethnicity, marital status, education and lead maternity provider. The differences by ethnicity may be related to the relatively low numbers of Māori and Asian-non-Indian participants. However, there may also be inequities in access to information for pregnant Māori women ${ }^{26}$ and cultural beliefs around pregnancy $\operatorname{loss}^{27} 28$ that may affect information acquisition for Asian-non-Indian women. We speculate that the differences by marital status may be related to an unmeasured factor, such as disparities in levels of social support and health-related behaviours for women in a single or cohabitating relationship compared with married women. ${ }^{29}$ A suggestion that supine position may differ by maternal education level ${ }^{30}$ due to reduced access and response to sleep-on-side information for women with a non-tertiary education may be a factor in the differences by education seen in our results. In addition, our finding that women with a hospital-based midwife/doctor as a lead maternity provider were more likely to report a supine going-to-sleep position indicates that the known benefits of midwifery continuity of care ${ }^{31}$ may include support for pregnant women to modify their going-to-sleep position from supine to nonsupine. A limitation of this survey is that because of the low prevalence of supine sleepers we were not able to undertake multivariable analysis to identify whether the above factors were independently associated with supine going-to-sleep position.

Receiving no sleep-on-side advice was associated with an over sixfold increase in odds of our pregnant participants reporting a supine going-to-sleep position last night (OR 6.70, 95\% CI 3.23 to 13.92). Therefore, it was encouraging that nearly $90 \%$ of women had received sleep-on-side advice, and of these two-thirds had changed their going-to-sleep position, with the majority reporting no major difficulty with the change. Importantly, nearly half who changed position had moved from the supine position associated with late stillbirth risk ${ }^{16}$ to a nonsupine position. Of women who needed help to modify their position, nearly $95 \%$ used pillows, which a previous New Zealand survey ${ }^{25}$ of pregnant women living in a multiethnic socioeconomic disadvantaged New Zealand region with a high stillbirth risk reported were readily available.

Health professionals' knowledge of supine going-tosleep position and the association with late stillbirth differed between professional groups. General practitioners and nurses reported the lowest levels of awareness, likely due to less contact with pregnant women compared with other health professionals who routinely provide pregnancy care. However, more than $90 \%$ of the health professionals who were aware of the association between supine going-to-sleep position and late stillbirth reported that they provided women with sleep-on-side advice. Three times as many health professionals had seen the sleep-on-side campaign pamphlet/poster $(61 \%$ vs $22 \%$ ) and video (9\% vs $3 \%$ ) compared with participants in the pregnant women's survey. This suggests that although most pregnant women surveyed did not recall the campaign resources, sleep-on-side advice was shared by their health professionals who had seen the resources.

It was also encouraging that nearly all pregnant women who reported that they did not change position after receiving sleep-on-side advice were already going to sleep in a non-supine position. This may be related to women's third trimester preference for a lateral sleep position. ${ }^{32-36}$ Indeed, comfort was a commonly cited reason for choice of late pregnancy going-to-sleep position by our participants and this is consistent with our prepublic health campaign survey. ${ }^{25}$ However, if comfort was the main factor influencing maternal going-to-sleep position, the rate of supine position would not have decreased since our previous New Zealand surveys. ${ }^{212}{ }^{25}$ Furthermore, the reported median gestation of change of going-to-sleep position was 20.0 weeks (IQR 15.0-25.0), although our public health campaign advised women to sleep on the side from 28 weeks' gestation. Therefore, it appears that the sleep-on-side campaign was an important factor in pregnant women's choice of going-to-sleep position.

Women's understanding of the rationale behind late pregnancy sleep-on-side advice was the main reason for their choice of a non-supine going-to-sleep position, reporting that it was 'better for baby'. Concern about providing pregnant women with sleep-on-side advice has been raised, ${ }^{37}$ due to the potential to cause or increase maternal anxiety, possibly leading to additional costs for antenatal testing and interventions. However, nearly $90 \%$ of our pregnant participants who had received sleep-on-side advice reported that this caused them little or no worry. We speculate that feeling informed and having autonomy over their going-to-sleep position may have reduced anxiety and enhanced the translation of the sleep-on-side information into late pregnancy sleep routines.

The statement from our IPD meta-analysis that 'swapping from the supine to the side-lying going-to-sleep position in late pregnancy is a simple intervention that can be self-managed by women with little difficulty in the home and requires no technology or equipment ${ }^{16}$ appears 
to have been realistic. This is supported by the steady decrease in the proportion of pregnant women in New Zealand, $\geq 28$ weeks' gestation with a singleton pregnancy, reporting a supine going-to-sleep position last night since our first New Zealand study. ${ }^{2}$ Although the absolute risk of late stillbirth with supine going-to-sleep position is relatively low in New Zealand, ${ }^{212}$ a decrease in supine position has been speculated ${ }^{38}$ to be a contributing factor to the significant national reduction in late stillbirth, from a rate of 3.4 to 2.4 per 1000 births since $2007 .^{20}$

Our findings suggest that providing women with the opportunity to protect their unborn babies may assist in the future reduction of stillbirth. Dissemination of sleep-on-side advice was supported by the large majority of health professionals providing pregnancy care. In turn, receiving sleep-on-side advice supported women to modify their late pregnancy going-to-sleep position without major difficulty or concern.

\section{CONCLUSION}

Most pregnant participants had received sleep-on-side advice and reported a non-supine going-to-sleep position that may reduce the risk of late stillbirth. Receiving advice and modifying going-to-sleep position resulted in no major difficulty or worry for the majority of women. The finding that some demographic groups of women (women of Māori, Asian-non-Indian ethnicity; single and cohabitating relationship status; hospital-based lead maternity provider; education overseas and primarysecondary level education) were associated with supine going-to-sleep position will enable tailored advice for these groups. The large majority of health professionals who were aware of the association between supine goingto-sleep position and stillbirth risk provided pregnant women with sleep-on-side advice.

\section{Author affiliations}

${ }^{1}$ Department of Obstetrics and Gynaecology, University of Auckland, Auckland, New Zealand

${ }^{2}$ Division of Women's Health, Counties Manukau District Health Board, Auckland, New Zealand

${ }^{3}$ Paediatrics: Child Health and Youth Health, University of Auckland, Auckland, New Zealand

${ }^{4}$ General Practice and Primary Health Care, University of Auckland, Auckland, New Zealand

${ }^{5}$ Vicki Culling Associates, Wellington, New Zealand

Twitter Robin S Cronin @rcroninaucklan1 and Vicki M Culling @VickiCNZ

Acknowledgements The authors thank all the participants who generously participated in the surveys in order to help us better understand how pregnant women and health professionals who provide care for pregnant women translate stillbirth prevention research into practice. We also thank the midwives, doctors and antenatal clinic support staff who assisted with our research at Counties Manukau Health, the Auckland District Health Board and LMC Services, Papatoetoe, Auckland.

Collaborators The Maternal Sleep Position Awareness Campaign Team includes the following: Jacqui Anderson, Midwifery Advisor, New Zealand College of Midwives; Saraid Black, Marketing and Communications Manager, Cure Kids New Zealand; Tania Cornwall, Coordinator, Sands New Zealand Auckland Central; Alison Eddy, Chief Executive, New Zealand College of Midwives; Tim Edmonds, Research and Innovation Director, Cure Kids New Zealand; Karen Hoare, Nurse Practitioner for Children and Young People, New Zealand; Catherine Jackson, Public Health,
Waitemata District Health Board, New Zealand; Minglan Li, Research Fellow, Obstetrics and Gynaecology, University of Auckland, New Zealand; Ngatepaeru Marsters, Pasifika Midwives Aotearoa, New Zealand; Isis McKay, General Manager, Women's Health Action, New Zealand; Lisa Paraku, Ngāti Tamaterā, Ngāti Porou, Consumer Representative on the Perinatal and Maternity Mortality Review Committee, Sands New Zealand Wellington-Hutt Valley; Liz Pearce, Parent Education and Operations Manager, Parents Centre Aotearoa, New Zealand; Bronwen Pelvin, Principal Advisor Maternity, Ministry of Health New Zealand; Helen Pulford, Childbirth Educator Liaison, New Zealand; Megan Tahere, Ngā Māia ki Tāmaki Makaurau Māori Midwives Chair, New Zealand.

Contributors RSC, JMDT, EAM and LM contributed to all aspects of the study design, with input from KFF, VC and The Maternal Sleep Position Awareness Campaign Team (MSPACT). EAM and LM obtained funding, with additional funding for the health practitioners' survey obtained by KFF. LM had overall responsibility for the study. RSC coordinated the running of the study with support from RT. RSC, SS and EB collected the data. RSC analysed the data with input from JW, JMDT, EAM and LM. RSC was responsible for the drafting of the manuscript. All authors, including the members of the MSPACT, gave approval for the final version of the manuscript.

Funding This work was supported by Cure Kids New Zealand (grant number 3577). The survey of health practitioners received additional funding from the Royal New Zealand College of General Practitioners Auckland Faculty Research and Education Charitable Trust, and a small donation was made to Sands New Zealand for each general practitioner response.

Competing interests None declared.

Patient consent for publication Not required.

Ethics approval Ethical approval was provided by the Auckland Health Research Ethics Committee (reference number 0000145) on 25/09/2019.

Provenance and peer review Not commissioned; externally peer reviewed.

Data availability statement Data are available upon reasonable request. The datasets analysed in this study are available on reasonable request to the corresponding author.

Supplemental material This content has been supplied by the author(s). It has not been vetted by BMJ Publishing Group Limited (BMJ) and may not have been peer-reviewed. Any opinions or recommendations discussed are solely those of the author(s) and are not endorsed by BMJ. BMJ disclaims all liability and responsibility arising from any reliance placed on the content. Where the content includes any translated material, BMJ does not warrant the accuracy and reliability of the translations (including but not limited to local regulations, clinical guidelines, terminology, drug names and drug dosages), and is not responsible for any error and/or omissions arising from translation and adaptation or otherwise.

Open access This is an open access article distributed in accordance with the Creative Commons Attribution Non Commercial (CC BY-NC 4.0) license, which permits others to distribute, remix, adapt, build upon this work non-commercially, and license their derivative works on different terms, provided the original work is properly cited, appropriate credit is given, any changes made indicated, and the use is non-commercial. See: http://creativecommons.org/licenses/by-nc/4.0/.

\section{ORCID iDs}

Robin S Cronin http://orcid.org/0000-0002-8304-8004

John M D Thompson http://orcid.org/0000-0001-6944-381X

Jessica Wilson http://orcid.org/0000-0003-4611-4495

\section{REFERENCES}

1 PMMRC. Te Pūrongo ā-Tau Tekau mā Toru O te Komiti Arotake mate Pépi, mate Whaea Hoki. Thirteenth annual report of the perinatal and maternal mortality review Committee: te tuku pūrongo mō te mate me te whakamate 2017. reporting mortality and morbidity 2017. Wellington: Health Quality \& Safety Commission, New Zealand Government, 2019.

2 Stacey T, Thompson JMD, Mitchell EA, et al. Association between maternal sleep practices and risk of late stillbirth: a case-control study. BMJ 2011;342:d3403.

3 Kerr MG, Scott DB, Samuel E. Studies of the inferior vena cava in late pregnancy. BMJ 1964;1:522-33.

4 Humphries A, Ali Mirjalili S, Tarr GP. The effect of supine positioning on maternal hemodynamics during late pregnancy. J Maternal-Fetal Neonat Med 2018:1-8. 
5 Humphries A, Mirjalili SA, Tarr GP, et al. Hemodynamic changes in women with symptoms of supine hypotensive syndrome. Acta Obstet Gynecol Scand 2020;99:631-6.

6 Milsom I, Forssman L. Factors influencing aortocaval compression in late pregnancy. Am J Obstet Gynecol 1984;148:764-71.

7 Lucchini M, Wapner RJ, Chia-Ling N-C, et al. Effects of materna sleep position on fetal and maternal heart rate patterns using overnight home fetal ECG recordings. Int J Gynaecol Obstet 2020;149:82-7.

8 Kinsella SM, Lee A, Spencer JAD. Maternal and fetal effects of the supine and pelvic tilt positions in late pregnancy. Eur J Obstet Gynecol Reprod Biol 1990;36:11-17.

9 Jeffreys RM, Stepanchak W, Lopez B, et al. Uterine blood flow during supine rest and exercise after 28 weeks of gestation. BJOG: Int J O\&G 2006:113:1239-47.

10 Stone PR, Burgess W, Mclntyre JPR, et al. Effect of maternal position on fetal behavioural state and heart rate variability in healthy late gestation pregnancy. J Physiol 2017;595:1213-21.

11 Carbonne $B$, Benachi $A$, Lévèque $M L$, et al. Maternal position during labor: effects on fetal oxygen saturation measured by pulse oximetry. Obstet Gynecol 1996;88:797-800.

12 McCowan LME, Thompson JMD, Cronin RS, et al. Going to sleep in the supine position is a modifiable risk factor for late pregnancy stillbirth; findings from the New Zealand multicentre stillbirth casecontrol study. PLoS One 2017;12:e0179396.

13 Gordon A, Raynes-Greenow C, Bond D, et al. Sleep position, fetal growth restriction, and late-pregnancy stillbirth: the Sydney stillbirth study. Obstet Gynecol 2015;125:347-55.

14 Heazell AEP, Li M, Budd J, et al. Association between maternal sleep practices and late stillbirth - findings from a stillbirth case-control study. BJOG: Int J Obstet Gy 2018;125:254-62.

15 O'Brien LM, Warland J, Stacey T, et al. Maternal sleep practices and stillbirth: findings from an international case-control study. Bir th2019;46:344-54.

16 Cronin RS, Li M, Thompson JMD, et al. An individual participant data meta-analysis of maternal going-to-sleep position, interactions with fetal vulnerability, and the risk of late stillbirth. EClinicalMedicine 2019;10:49-57.

17 Cure Kids. 'Sleep on side stillbirth prevention campaign' launched nationally New Zealand, 2018. Available: https://curekids.org.nz/ news/sleep-on-side-stillbirth-prevention-campaign-launchednationally/

18 Health Promotion Agency and the Ministry of Health. Sleep on side when baby's inside New Zealand, 2018. Available: https:// www.healthed.govt.nz/resource/sleep-side-when-babys-inside-0 [Accessed Aug 2019].

19 Tommy's. Sleep on side - the research behind the campaign London, 2017. Available: https://www.tommys.org/pregnancy-information/ sleep-side/sleep-side-research-behind-campaign [Accessed Nov 2017].

20 PMMRC. Fourteenth annual report of the perinatal and maternal mortality review Committee. te Pūrongo $\bar{a}$-Tau Tekau mā Whā O te Komiti Arotake mate Pēpi, mate Whaea Hoki reporting mortality and morbidity 2018. te tuku pürongo mō te mate me te whakamate 2018. Wellington: Health Quality \& Safety Commission, New Zealand Government, 2021

21 Marteau TM, Bekker $\mathrm{H}$. The development of a six-item short-form of the state scale of the Spielberger State-Trait anxiety inventory (STAI). Br J Clin Psychol 1992;31:301-6.

22 Ministry of Health. Ethnicity data protocols for the health and disability sector. New Zealand: Ministry of Health Wellington, 2004.

23 World Health Organisation. Obesity: preventing and managing the global epidemic. Report of a who consultation. who technical report series 894. Geneva: World Health Organisation, 2000.

24 Mclntyre JPR, Ingham CM, Hutchinson BL, et al. A description of sleep behaviour in healthy late pregnancy, and the accuracy of selfreports. BMC Pregnancy Childbirth 2016;16:1-8.

25 Cronin RS, Chelimo C, Mitchell EA, et al. Survey of maternal sleep practices in late pregnancy in a multi-ethnic sample in South Auckland, New Zealand. BMC Pregnancy Childbirth 2017;17:190.

26 Cronin RS, Li M, Wise M, et al. Late stillbirth post mortem examination in New Zealand: maternal decision-making. Aust N Z J Obstet Gynaecol 2018;58:667-73.

27 Tseng Y-F, Hsu M-T, Hsieh Y-T, et al. The meaning of rituals after a stillbirth: a qualitative study of mothers with a stillborn baby. J Clin Nurs 2018;27:1134-42.

28 Rice PL. Death in birth: the cultural construction of stillbirth, neonatal death, and maternal death among Hmong women in Australia. Omega 2000;41:39-57.

29 Raatikainen K, Heiskanen N, Heinonen S. Marriage still protects pregnancy. BJOG 2005;112:1411-6.

30 Chappell LC, Smith GCS. Should pregnant women sleep on their left? BMJ 2011;342:d3659.

31 Sandall J, Soltani H, Gates S, et al. Midwife-led continuity models versus other models of care for childbearing women. Cochrane Database Syst Rev 2016;4:CD004667.

32 Mills GH, Chaffe AG. Sleeping positions adopted by pregnant women of more than 30 weeks gestation. Anaesthesia 1994;49:249-50.

33 Warland J, Dorrian J. Accuracy of self-reported sleep position in late pregnancy. PLoS One 2014;9:e115760.

34 Matsuo K, Shimoya K, Ushioda N, et al. Maternal positioning and fetal positioning in utero. J Obstet Gynaecol Res 2007;33:279-82.

35 O'Brien LM, Warland J. Typical sleep positions in pregnant women. Early Hum Dev 2014;90:315-7.

36 Ogita S, Imanaka M, Takebayashi T, et al. Significance of exercise and bed rest in pregnancy. study on the lying postures of gravidas during sleep. Ann Physiol Anthropol 1990;9:93-8.

37 Silver RM, Hunter S, Reddy UM, et al. Prospective evaluation of maternal sleep position through 30 weeks of gestation and adverse pregnancy outcomes. Obstet Gynecol 2019;134:667-76.

38 PMMRC. Eleventh annual report of the perinatal and maternal mortality review Committee: reporting mortality 2015. Wellington: Health Quality \& Safety Commission, New Zealand Government, 2017 